E. Tierney MB B CH FFARCSI, G. Lewis MB B CH FRCPC, J. B. Hurtig MD FRCPC, D. Johnson MD FRCSC

\title{
Femoral nerve block with bupivacaine 0.25 per cent for post- operative analgesia after open knee surgery
}

An assessment was made, in a randomised double-blind fashion, of the pain relief afforded by femoral nerve block (FNB) performed at the end of ligament reconstruction of the knee, using 0.25 per cent bupivacaine in sen patients, and normal saline in ten patients. All patiens commenced "contintwus passive motion" (CPM) of the aperated knee after arrival in the Recovery Room. The postoperative analgesic requirement, both for intravenous fentanyl in the Recovery Room, and intramuscular and oral analgesia on the ward, was then studied. The time interval between FNB and first dose of analgesia was significantly longer in the bupivacaine group than in the control group. The bupivacaine group also required significantly less intravenous fentanyl in the Recovery Room. On the ward. there was no difference between the two groups in the total dose of intramuscular meperidine given in the first 12 hours postoperatively. We conclude that femoral nerve block is a useful adjunct in pain management after ligament reconstruction of the knee, especially in tite early postoperative period, but does not decrease the total intramuscular dose of analgesia in the first 12 postopcrative hours.

\section{Key words}

SURGERY: orthopaedic; FEMORAL NERVE: blockade; ANALGESIA: postoperative.

From the Department of Anaesthesia and the Division of Orthopaedic Surgery, Ottawa Civic Hospital and the University of Ottawa, Ottawa, Ontario.

Address correspondence 10: Dr. Geraint Lewis, Department of Anaesthesia, C3, Ottawa Civic Hospital, 1053 Carling Ave., Ottawa, Ontario, KIY 4E9.
Pain after knee ligament reconstruction is often severe. In our hospital, these patients, after operation, are immediately subjected to continuous passive motion (CPM) of their knee. This ensures slow but steady flexion and extension of the joint. In an attempt to prevent the pain induced by this continuous motion, it has been our practice to perform a femoral nerve block (FNB) at the end of surgery, just before awakening the patient. Although clinical impression suggests an improvement in postoperative analgesia, the efficacy of FNB for open knee surgery has not been objectively assessed. Rooks and Fleming' evaluated combined sciatic and femoral nerve blockade in acute knee injury, and found that all patients obtained adequate analgesia and muscle relaxation for complete evaluation of their injury, and that 92 per cent obtained total analgesia of the knee. Tondare and Nadkami ${ }^{2}$ used femoral nerve block for immobilization of fractured femoral shafts, and found that only one-fifth of their patients needed analgesic supplementation. Ringrose and $\mathrm{Cross}^{3}$ studied the use of this block after knee ligament reconstruction in a controlled, non-randomized, non-blinded fashion. In patients receiving the block after induction of anaesthesia, they concluded that FNB significantly reduced opiate requirements in the first 24 postoperative hours. However, this finding may have been partly due to the administration of differing amounts of intraoperative narcotics. Therefore, in an attempt to evaluate femoral nerve block in our patients, the following study was undertaken.

\section{Methods}

All patients were scheduled for elective knee ligament reconstruction by the same surgeon. All patients were of ASA physical status category 1 and most had developed their knee problem as a result of a sporting injury. The trial was approved by our hospital research ethics committee, and informed consent was obtained from each patient prior to enrollment.

Patients received diazepam $10 \mathrm{mg}$ Po 90 minutes prior to induction. After insertion of an intravenous line, each 
patient was given a defasciculating dose of d-tubocurarine $(3.0-4.5 \mathrm{mg})$, followed by $1.0-1.25 \mathrm{mg}$ droperidol and $2 \mu \mathrm{g} \cdot \mathrm{kg}^{-1}$ of fentanyl. Anaesthesia was then induced with thiopentone $4-6 \mathrm{mg} \cdot \mathrm{kg}^{-1}$, followed by succinylcholine $1-2 \mathrm{mg} \cdot \mathrm{kg}^{-1}$. Patients were then ventilated with oxygen, nitrous oxide and isoflurane using a circle with absorber circuit, at a rate of 8 breath $\cdot \mathrm{min}^{-1}$ and a tidal volume of $10 \mathrm{ml} \cdot \mathrm{kg}^{-1}$. Use and choice of non-depolarizing neuromuscular relaxant was at the discretion of the individual anaesthetist.

The femoral nerve block was performed at the end of the operation, before removal of the surgical tourniquet. The FNB was performed in each case according to the method described by Moore, ${ }^{4}$ in which the point of injection is one inch below the inguinal ligament, immediately lateral to the femoral artery. The hospital pharmacy prepared twenty $20 \mathrm{ml}$ ampoules, ten containing bupivicaine 0.25 per cent plain and ten normal saline. The anaesthetist and other staff, including the postoperative nurses, were blinded as to their contents. The twenty $\mathrm{ml}$ of solution was injected in a fan-wise fashion, infiltrating the solution in a block of tissue one and a quarter inches deep and one inch lateral to the femoral artery. A peripheral nerve stimulator was not used to locate the femoral nerve.

Anaesthesia was then discontinued, and the patient transferred to Recovery Room. On arrival, continuous passive motion (CPM) of the knee was immediately commenced with a CPM machine (Cogemo SA, Charleville, France ${ }^{\circ}$ ), and continued throughout the 12-hour study period. This machine is a motor-driven frame, which moves back and forth ensuring alternate flexion and cxtension of the affected knee joint. In the Recovery Room, patients were given fentanyl IV by nursing staff, in aliquots of $25 \mu \mathrm{g}$, on demand for pain, until they were deemed to be comfortable.

On the ward, meperidine 50-100 $\mathrm{mg}$ IM was given on demand for pain, by ward nursing staff, who were also unaware of the nature of the block. When the patient was able to tolerate oral medication, usually $8-16$ hours after surgery, the IM meperidine was replaced by an acetaminopnen, codeine and caffeine combination (Tylenol no. $\left.3^{\circ}\right)$.

The total number of analgesic doses given to each patient in the first 12 postoperative hours, included intravenous fentanyl, intramuscular meperidine, and oral acetaminophen compound, was recorded for both groups of patients, and the results were analyzed using the Kruskal-Wallis and Mann-Whitney non-parametric comparative tests.

\section{Results}

Twenty patients were studied. Ten received bupivacaine, and ten saline. All patients received intravenous fentanyl
TABLE Femoral nerve block with placebo versus bupivacaine (mean $\pm \mathrm{SD})$

\begin{tabular}{|c|c|c|c|}
\hline & $\begin{array}{l}\text { Placebo } \\
n=10\end{array}$ & $\begin{array}{l}\text { Bupivacaine } \\
n=10\end{array}$ & p valice \\
\hline $\begin{array}{l}\text { Induction to FNB (min) } \\
\text { FNB to l st }\end{array}$ & $107 \pm 26$ & $106 \pm 24$ & NS \\
\hline $\begin{array}{l}\text { Postop analgesia (min) } \\
\text { Fentanyl in }\end{array}$ & $61 \pm 56$ & $164 \pm 135$ & $<0.01$ \\
\hline $\begin{array}{l}\text { Recovery Room }(\mu g) \\
\text { Meperidine }\left(\mathrm{mg} \cdot \mathrm{kg}^{-1}\right)\end{array}$ & $33 \pm 31$ & $8 \pm 17$ & $<0.05$ \\
\hline $\begin{array}{l}\text { in Ist } 12 \mathrm{hr} \text { after FNB } \\
\text { No. of oral unalgesic } \\
\text { doses in } 1 \mathrm{st} 12 \mathrm{hs} \\
\text { after FNB }\end{array}$ & $2.6 \pm 1.7$ & $2.5 \pm 1.6$ & NS \\
\hline
\end{tabular}

$2 \mu \mathrm{g} \cdot \mathrm{kg}^{-1}$ at the time of induction of anaesthesia. The mean time interval from induction of anaeșthesia to performance of the FNB was not significantly different between groups (Table). Comparing groups with respect to their opiate requirements in the Recovery Room (Table and Figure 1), seven of ten patients in the placebo group received opiate supplementation, compared with only two of ten in the bupivacaine group. One patient in the placebo group was mistakenly ordered meperidine instead of fentanyl, and received a total of $10 \mathrm{mg}$ IV. This patient was not included in the statistical comparison of Recovery Room opiate administration.

There was a significant difference $(p<0.01)$ in the interval between FNB and the first postoperative parenteral analgesic in the two groups, the mean inverval in the bupivacaine group being $164 \pm 135$ minutes, versus $61 \pm$ 46 minutes in the placebo group. However, once back on the ward, differences between the two groups became less apparent. There was no difference in the total dose of meperidine (absolute or $\mathrm{mg} \cdot \mathrm{kg}^{-1}$ ), between the two groups when their requirements were compared for the first 12 postoperative hours.

Comparing the total number of analgesic administrations (intramuscular and oral), received by the two groups over the 12 hours (Figure 2), the placebo group initially

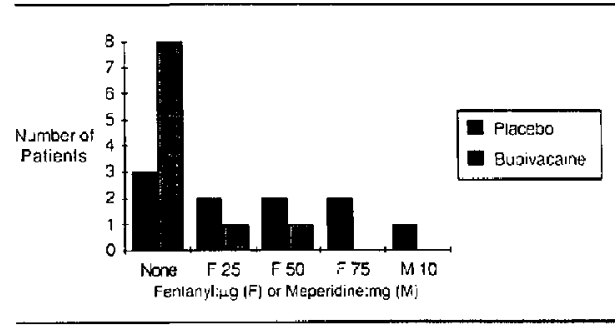

FIGURE I Recovery Room opiate requirements. 


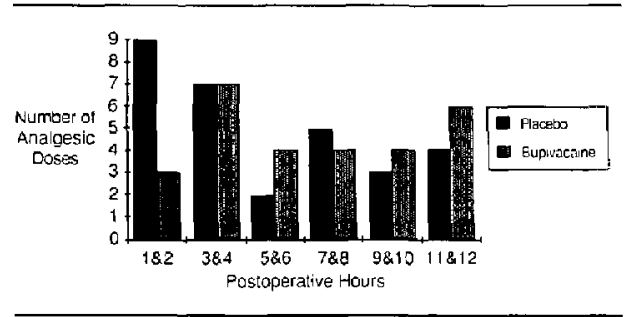

FIGURE 2 Total number of analgesic administrations in the first 12 postoperative hours.

required more analgesia, but differences between the groups became less apparent during the remainder of the 12-hour period. The small number of patients, however, precluded meaningful statistical analysis of this phenomenon.

\section{Discussion}

The principles and technique used for femoral nerve block in this study are well recognized. ${ }^{5} \mathrm{~A}$ peripheral nerve stimulator was not used to signify a successful femoral nerve block with bupivacaine, as we felt it might unblind the anaesthetist, although it has been documented that a saline placebo can also abolish the twitch response. ${ }^{6}$ We also felt that the method of the block, that is, a fan-wise injection, might limit the usefulness of a stimulator. Femoral nerve damage after FNB is unreported, and the use of a FNB in an anaesthetized patient without using a peripheral nerve stimulator has been described. ${ }^{3}$

Since the time interval between induction of anaesthesia and the performance of the femoral nerve block was not different between groups, time differences did not affect the degree of analgesia on arrival in the recovery room. In addition, all patients received the same amount of intraoperative fentanyl, also eliminating this as a confounding variable.

One of the most impressive differences between the two groups was their differing analgesic requirements during their one-hour Recovery Room stay. Patients who receive a bupivacaine block, by virtue of having a lesser intravenous fentanyl requirement, might be at less risk of Recovery Room complications such as respiratory depression or aspiration, as well as suffering less from the more minor side-effects of opiates. However, we did not address this issue in this study.

The number of analgesic administrations over the first 12 postoperative hours demonstrated that the analgesic requirement of the placebo group tended to decrease, whereas the requirement of the bupivacaine group increased with time. From the eighth to the twelfth hours, the number of analgesic administrations to the bupivacaine group was greater than that of the placebo group. Although the small patient sample precluded statistical conformation of this trend, this may have reflected the gradual onset of pain after the analgesic effects of the block ended. Indeed, the pain relief in the bupivacainc group may have not lasted much longer than the duration of their stay in the Recovery Room. The addition of epinephrine to the bupivacaine, to prolong analgesia, may warrant future study.

As an alternative, Patel et al. ${ }^{7}$ reported the use of the "three-in-one block" with or without lateral femoral cutaneous nerve block for outpatient knee arthroscopy, comparing it with general anaesthesia. They found that the regional anaesthesia groups required less postoperative analgesics, had less nausea and vomiting, and were discharged more quickly. They also noted that the separate block of the lateral femoral cutaneous nerve provided better surgical anaesthesia than the "three-inone block" alone.

In conclusion, we feel that femoral nerve block offers a technically easy and safe method of providing significant early pain relief for patients rccovering from knce ligament reconstruction. For longer-term pain relief, however, especially in the presence of continuous passive motion of the operated knee, femoral nerve block would appear to be inadequate by itself, although it might be more effective in the case of a motionless knee. We feel that the addition of adrenaline to prolong the duration of analgesia, and analgesia provided by combining femoral nerve block with blockade of the sciatic nerve and/or the lateral femoral cutaneous nerve should be studied in this context.

\section{Acknowledgements}

Our grateful thanks are due to Ms. A. Sharatmadar, our statistician, and to Winthrop Laboratories Ltd. for their support.

\section{References}

I Khoo ST, Brown TC. Femoral nerve block - the anatomical basis for a single injection technique. Anaesth Intensive Care 1983; 11:40-2.

2 Ringroje NH, Cross $M J$. Femoral nerve block in knee joint surgery, Am J Sports Med 1984; 12: 398-402.

3 Rooks $M$. Fleming $L L$. Evaluation of acute knee injuries with sciatic/femoral nerve blocks. Clin Orthop 1983; 179: 185-8.

4 Tondare AS, Nadkarni AV. Femoral nerve block for fractured shaft of femur. Can Anaesth Soc J 1982; 29: 270-1.

5 Moore DC. Regional Black. 4th ed. Springfield: Charles C. Thomas, 1976. 
6 Pither C, Raj PP, Ford DJ. The use of peripheral nerve stimulators for regional anaesthesia: a review of experimental characteristics, techniques and clinical applications. Regional Anesthesia 1985: 10:57.

7 Patel NJ, Flashburg MH, Paskin S, Grossman R. A regional anesthet ic technique compared to general anaesthesia for outpatient knee arthroscopy. Anesth Analg 1986; 65: 185-7.

Résumé

Une épreuve randomisée à double insu a permis d'évaluer le soulagement de la douleur offert par un bloc fémoral à la fin de l'intervention chirurgicale à genou ouvert. On avait administré de la bupivacaine 0.25 pour cent, à dix patients et une solution salée a l'autre dix. On a ensuite procédé à l'étude des besoins post-opératiores en analgésiques, plus particuliérement en fentanyl intraveineux dans la salle de réveil, et en mépéridine intramusculaire dans l'unité de soins. Dans le groupe ayant reçu de la bupivacaine, l' intervalle entre le bloc fêmoral et la première dose d' analgésique fut sensiblement plus longue que dans le groupe ayant reçu une solution salèe. Le groupe traité à la bupivacaine eut aussi bien moins besoin de fentamyl dans la salle de réveil. On n'a pas noté de différence entre les deux groupes quanı à la dose totale de mépéridine adminisirée par voie intramusculaire pendant les 12 heures suivant l'opération. Nous pouvons en conclure que le bloc fémoral ess une méthode supplémentaire de soulagement de la douleur après l'opération à genou ouvert, plus particulièrement pendant la phase plus vulnérable de réveil et les premières heures de retour à l' unité de soins, mais qu' elle ne diminue cependant par la dose torale $d$ analgésique intramusculaire nécessaire pendant les 12 heures qui suivent l'intërvention chirurgicate. 